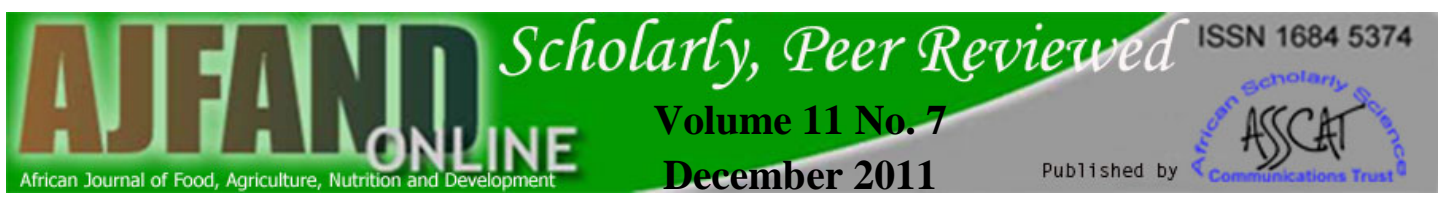

\title{
EFFECT OF CUTTING SHAPES AND THICKNESSES ON THE QUALITY OF MINIMALLY PROCESSED PINEAPPLE (Ananas comosus), cv. 'QUEEN VICTORIA'
}

\author{
Danyen MS ${ }^{1}$, Boodia $\mathrm{N}^{2 *}$ and A Ruggoo ${ }^{2}$
}

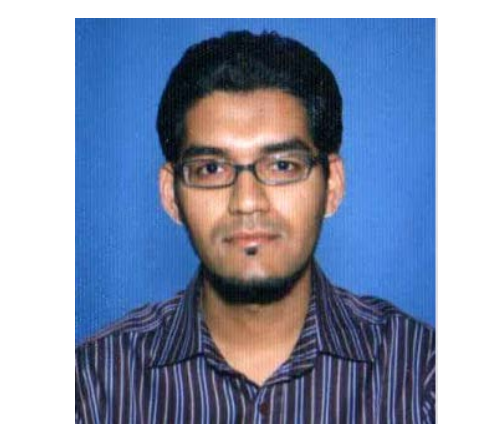

Danyen Shameer Mamade

*Corresponding Author Email: n.boodia@uom.ac.mu

${ }^{1}$ Department of Agricultural and Food Sciences, Faculty of Agriculture, University of Mauritius, Réduit, Mauritius.

${ }^{2}$ Department of Agricultural Production and Systems, Faculty of Agriculture, University of Mauritius, Réduit, Mauritius. 


\section{ABSTRACT}

Cutting shape and size are physical factors that influence the keeping quality of minimally processed fruits and vegetables. Since these factors have not been studied as determinants of the keeping quality of minimally processed pineapples (MPP) cV. 'Queen Victoria', this study was conducted. A 2 × 2 factorial treatment structure laid on a randomized block design (RBD) was used. The treatments, which were blocked by days, were combinations of two cutting shapes (slices and chunks) and two thicknesses (5 mm and $10 \mathrm{~mm}$ ). Pineapples of 25 - 50\% ripeness were minimally processed to give rise to the treatments, which were then vacuum-packed at $47.5 \mathrm{kPa}$ in laminated Low Density Polyethylene (LDPE) vacuum bags and stored at $4 \pm 1^{\circ} \mathrm{C}$ for 12 days. Quality changes were evaluated at three-day intervals over a storage period of 12 days. Translucency score was evaluated by comparison method against standard colour charts. Electrical conductivity of leachate (ECL), firmness and $\mathrm{pH}$ were measured instrumentally. Ascorbic acid (AA) content was determined by titration with dichlorophenolindophenol (DCPIP) dye. Yeasts and moulds counts (YMC) were also enumerated using the classical standard method. Data were analysed using analysis of variance (ANOVA), and sum of squares due to treatment were split into main effect cutting shape, main effect thickness and interaction effect. All the keeping quality attributes of the MPP were significantly affected by storage time $(\mathrm{p}<0.001)$. Cutting shape also significantly affected translucency score $(\mathrm{p}<0.01)$, firmness $(p<0.01)$ and YMC $(p<0.01)$. Slices were firmer and had the lowest translucency score and minimized fungal growth as opposed to chunks. No significant interaction effect $(\mathrm{p}>0.05)$ was observed between cutting shapes and thicknesses on translucency score, firmness and YMC of the MPP. However, a significant interaction effect was noted between these two variables on ECL $(\mathrm{p}<0.05)$ and AA content $(\mathrm{p}<0.001)$. A thickness of $10 \mathrm{~mm}$ exhibited lower translucency score, higher ECL, reduced firmness and lower AA losses. $\mathrm{pH}$ was not significantly affected $(\mathrm{p}>0.05)$ by cutting shapes and thicknesses. Ten-mm slices maintained all the above-stated quality parameters, except ECL and $\mathrm{pH}$, when stored at $4 \pm 1^{0} \mathrm{C}$ for 12 days.

Key words: Minimally processed pineapple, shape, thickness 


\section{INTRODUCTION}

Consumer demand for convenient, fresh quality and healthy foods has led to the emergence of minimal processing, which involves the washing, peeling, cutting or shredding of a food before packaging and storage at low temperature [1]. Minimal processing is becoming increasingly popular amongst consumers due to the retention of the nutritional quality and sensory characteristics namely appearance, texture and flavour, as a result of reduced dependence on chemicals and heat treatments [2]. Pineapple (Ananas comosus), a non-climacteric tropical fruit, is a good candidate for minimal processing given that peeling, eyes removal and size reduction activities during processing are tedious and time-consuming.

One of the major problems faced by the manufacturers of MPP is the limited shelf life $[3,4]$. Shelf-life is determined by the time required for one or more quality characteristics of a food to reach undesirable states [5]. Minimally processed pineapples (MPP) have a short shelf-life of 2-3 days under ambient shop conditions [6]. Operations involved in the preparation of MPP cause injury and damage to tissues, affecting physiological activities like tissue respiration and lead to various biochemical pathways, resulting in losses of sensory attributes [2, 7, 8, 9]. Microbial spoilage is also enhanced and the marketability of the produce is thus reduced [10].

Other factors that influence produce deterioration are the cutting shape and thickness adopted during minimal processing [9, 11]. Smaller and thinner fresh-cut produce with no chemical treatments can result in enhanced deterioration. To stabilize the microbiological and sensory quality of MPP with reduced use of chemicals, modified atmosphere packaging together with low storage temperature of $4^{\circ} \mathrm{C}$ can be used [12].

Although cut-type and size of MPP influence the purchasing decision of customers since different recipes require different produce geometry, few studies have addressed separately the effect of cutting-shapes [1, 13] and cutting dimensions [14] on quality changes. Recently, the effects of cutting-shapes and storage temperature on metabolic activities of minimally processed 'Perola' pineapple were determined and it was found that respiration rate of pineapple slices was similar to that of pineapple chunks when stored for 14 days at $4 \pm 1^{0} \mathrm{C}$ [15]. However, there is limited information regarding the effect of cutting shape and thickness on the quality changes of minimally processed 'Queen Victoria' pineapple. Therefore, the objectives of this study were to determine the effects of cutting shapes and thicknesses, and their interaction on the keeping quality of vacuum-packed MPP stored at $4 \pm 1^{\circ} \mathrm{C}$.

\section{MATERIALS AND METHODS}

\section{Pineapple cv. ‘Queen Victoria' samples}

Pineapple fruits cv. 'Queen Victoria' of 25 - 50\% yellow coloration were chosen for this study as it is the most commonly grown cultivar in Mauritius. Thirty pineapples were randomly selected from three independent harvest batches coming from 10 different farms in Camp de Masque (Flacq), which is a major production zone of pineapples locally. All the farms were in the same geographic location $\left(20.24^{\circ} \mathrm{S}\right.$; 


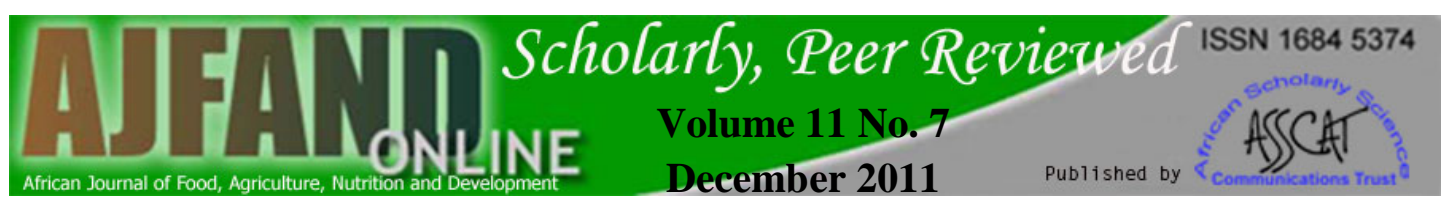

$57.66^{\circ} \mathrm{E}$; and altitude $\left.181 \mathrm{~m}\right)$. Once harvested early in the morning, the pineapples were placed upright in clean plastic crates. Gaps between the fruits in the crates were filled with paper to prevent mechanical shock during travel. The crates were then transported at ambient temperature $\left(26 \pm 2{ }^{\circ} \mathrm{C}\right)$ to the Food Technology laboratory, University of Mauritius within one hour, where the pineapples were used for the experiment.

\section{Experimental design}

The experimental design used was a randomized block design. A 2 x 2 factorial treatment structure was used, whereby the treatments were combinations of two cutting-shapes and two thicknesses. The four treatment combinations were blocked by days (day 0, 3, 6, 9 and 12) with three replicates per treatment combination and they were: T1 - 5 mm slices; T2 - 10 mm slices; T3 - 5 mm chunks; and T4 - $10 \mathrm{~mm}$ chunks.

\section{Pineapple processing}

The pineapples were graded to eliminate defective and spoilt fruits before adopting the Agricultural Research and Extension Unit's (AREU) [16] protocol for the minimal processing of pineapples. The pineapples were then mixed homogeneously prior to minimal processing. Strict personal hygiene was observed before, during and after the fruit processing to prevent cross contamination. Clean white overall, hair net and disposable gloves were worn. The fruits were peeled and sliced to 5 and $10 \mathrm{~mm}$ with a sharp stainless steel knife. Some of the slices were then made into chunks by cutting a slice into eight equal parts. The cut-pineapples were chlorine-sanitized for 2 minutes, rinsed with boiled and cooled water for 30s and surface-dried with lint-free kitchen paper. The pineapples were then vacuum-packed at $47.5 \mathrm{kPa}$ in laminated Low Density Polyethylene (LDPE) bags (Plaspak, Mauritius) under the four treatments using a vacuum packaging machine (Multivac A300, Wolfertsschwenden, Germany). The oxygen transmission rate (OTR) for the LDPE bags was $35 \mathrm{~cm}^{3} / \mathrm{m}^{2} / 24 \mathrm{~h}$ at $23^{\circ} \mathrm{C}$. The number of packages for each treatment was 18, each one having approximately $100 \mathrm{~g}$ of fruit. The samples were eventually stored in an incubator at $4 \pm 1^{\circ} \mathrm{C}$. Three packs from each treatment were selected randomly in the incubator and were evaluated for quality changes on a 3-day interval over a storage period of 12 days.

\section{Quality analysis}

\section{Translucency score estimation}

Translucency affects the visual appearance of MPP and it was estimated by comparison against standard pineapple translucency charts designed by Haff et al. [17] and Kader [18]. The rating was defined as score 1: not translucent and score 5: $>75 \%$ translucency). After specific storage time, random samples of treated MPP were matched against the chart. The flesh rating was carried out by assigning the most appropriate score listed in the chart to each slice or five chunks.

\section{Electrical conductivity of leachate (ECL)}

When plant tissues are bruised, the sap is leached out of the cell. The leachate is rich in mineral ions, sugars, other nutrients and water and thus can conduct electricity. Electrical conductivity of leachate produced can therefore be used indirectly to 
determine the extent of cellular damage in minimally processed produce [19]. The greater the damage caused to the membranes, the greater the leachate volume and ECL. The conductivity of the leachate formed during the storage of the MPP was measured in $\mu \mathrm{S} / \mathrm{cm}$ using the method described by Clesceri et al. [20] with slight modifications. One milliliter $(\mathrm{ml})$ of the accumulated leachate was transferred into a cell that had been washed with $0.01 \mathrm{M} \mathrm{KCl}$. De-ionised water was used to dilute the leachate up to a total volume of $5 \mathrm{ml}$ and the resulting solution was vortexed. The temperature and the electrical conductivity of the sample were recorded with a calibrated conductivity meter (Jenway Ltd, Felsted, Essex, England).

\section{Firmness}

A calibrated penetrometer (Stanhope-Seta 17000-0, England) was used to measure the firmness of the tissues of the MPP at ambient temperature $\left(23 \pm 1^{\circ} \mathrm{C}\right)$. Firmness was expressed as the penetration distance, measured in millimetres $(\mathrm{mm})$, required to manually depress the sample in five seconds with the shaft of diameter $9.5 \mathrm{~mm}$. Five measurements were made on each pineapple slice while two on each of the five randomly selected chunks. Percentage maximum penetration distance (\% MPD) for each treatment was calculated as follows:

$$
\% \mathrm{MPD}=\frac{\text { Mean penetration distance }}{\mathrm{X}} * 100
$$

where $\mathrm{X}$ is the thickness of the MPP in $\mathrm{mm}$

$$
p H
$$

The method described by International Standards Organisation (ISO) [21] was adopted in measuring the $\mathrm{pH}$ of each replicate. About $10 \mathrm{~g}$ of fruit was blended for 30s in a blender (Philips, England). The paste was filtered through a muslin cloth into a $50 \mathrm{ml}$ beaker, which was then covered with a cling film. The $\mathrm{pH}$ and the temperature of the juice were recorded twice using a calibrated $\mathrm{pH}$ meter (Hanna Instruments, USA) equipped with an automatic temperature compensator and a calibrated digital food thermometer respectively after stirring the juice.

\section{Ascorbic Acid content (AA)}

The Association of Official Analytical Chemists (AOAC) [22] official method of analysis of AA content by the 2,6-dichlorophenolindophenol titration was adopted. In order to ensure minimal AA loss, the glassware used was covered with aluminium foil. Three determinations were carried out for each replicate. The AA content was expressed as mg per $\mathrm{kg}$ fresh weight of fruit. Percentage mean AA loss was also calculated for each treatment after the 12 storage days.

Yeasts and moulds count (YMC)

The ISO [23] method was used for the enumeration of yeasts and moulds in the MPP with some modifications. Ten g sample from each replicate was pummeled with $90 \mathrm{ml}$ of physiological saline ( $\mathrm{NaCl}, 9 \mathrm{~g} / \mathrm{L}$ ) in a stomacher (Seward 400, Brinkmann, Westbury, New York) for 30s to obtain a mother sample, which was then serially diluted with physiological saline. Fungal agar was the medium used and the pourplate technique was adopted. The procedure was duplicated using same inoculum 
prepared from each replicate. The saline and fungal agar were prepared and incubated as directed by the manufacturer (Sigma Laboratories, Germany). All the steps were carried under sterile conditions. After incubation for 3-5 days at $25^{\circ} \mathrm{C}$, petri plates having colony-forming units (CFUs) within the range of 30 to 300 were considered.

\section{Statistical analysis}

The data for ECL and YMC were log-transformed before the analysis so that the assumptions of the analysis of variance (ANOVA) were satisfied. Raw data and those log-transformed were analyzed using ANOVA provided in the statistical software, MINITAB ${ }^{\circledR} 14.1$ (Minitab, Inc., State College, PA). Sum of squares due to treatment were split into main effect cutting-shape, main effect thickness and interaction effect between the two variables. When interaction effect between cutting-shape and thickness for a particular parameter was found to be significant, main effects were not considered. The significance was defined at $\mathrm{p}<0.05$ unless stated otherwise.

\section{RESULTS}

\section{Effect of cutting-shape}

The main effect due to cutting shape affected significantly translucency score $(p<0.01)$, firmness $(p<0.01)$ and YMC $(p<0.01)$. Pineapple slices were found to exhibit less translucent tissues, lower firmness loss and favoured minimal fungal growth as compared to chunks (Table 1).

\section{Effect of thickness}

The main effect due to thickness influenced significantly translucency score $(p<0.01)$ and firmness $(\mathrm{p}<0.05)$. Ten $\mathrm{mm}$ thickness significantly reduced the translucency score compared to $5 \mathrm{~mm}$ thickness. Ten mm slices and chunks retained its firmness during the 12 storage days since it had the lowest \% mean penetration distance (Table 2).

\section{Interaction effect between cutting shape and thickness}

The interaction effect between cutting shape and thickness was significant for ECL $(\mathrm{p}<0.05)$ and ascorbic acid content $(\mathrm{p}<0.001)$. Doubling the thickness of pineapple chunks led to a significant increase $(\mathrm{p}<0.05)$ in the ECL as opposed to slices, whose cutting size had no effect on the mean ECL. When the thickness of any of the two cutting-shapes doubled, the ascorbic acid content of the fresh-cut pineapple increased (Table 1). Table 2 shows that $10 \mathrm{~mm}$ slices had the lowest \% ascorbic acid loss after 12 storage days.

\section{Effect of storage time}

\section{Translucency score}

Figure 1a shows that the four treated MPPs were not translucent (translucency score = 1) at day 0 but during the 12 storage days, their translucency score increased significantly $(\mathrm{p}<0.001)$. T4 had the highest mean translucency score after 12 storage days, followed by T3, T1 and T2. 

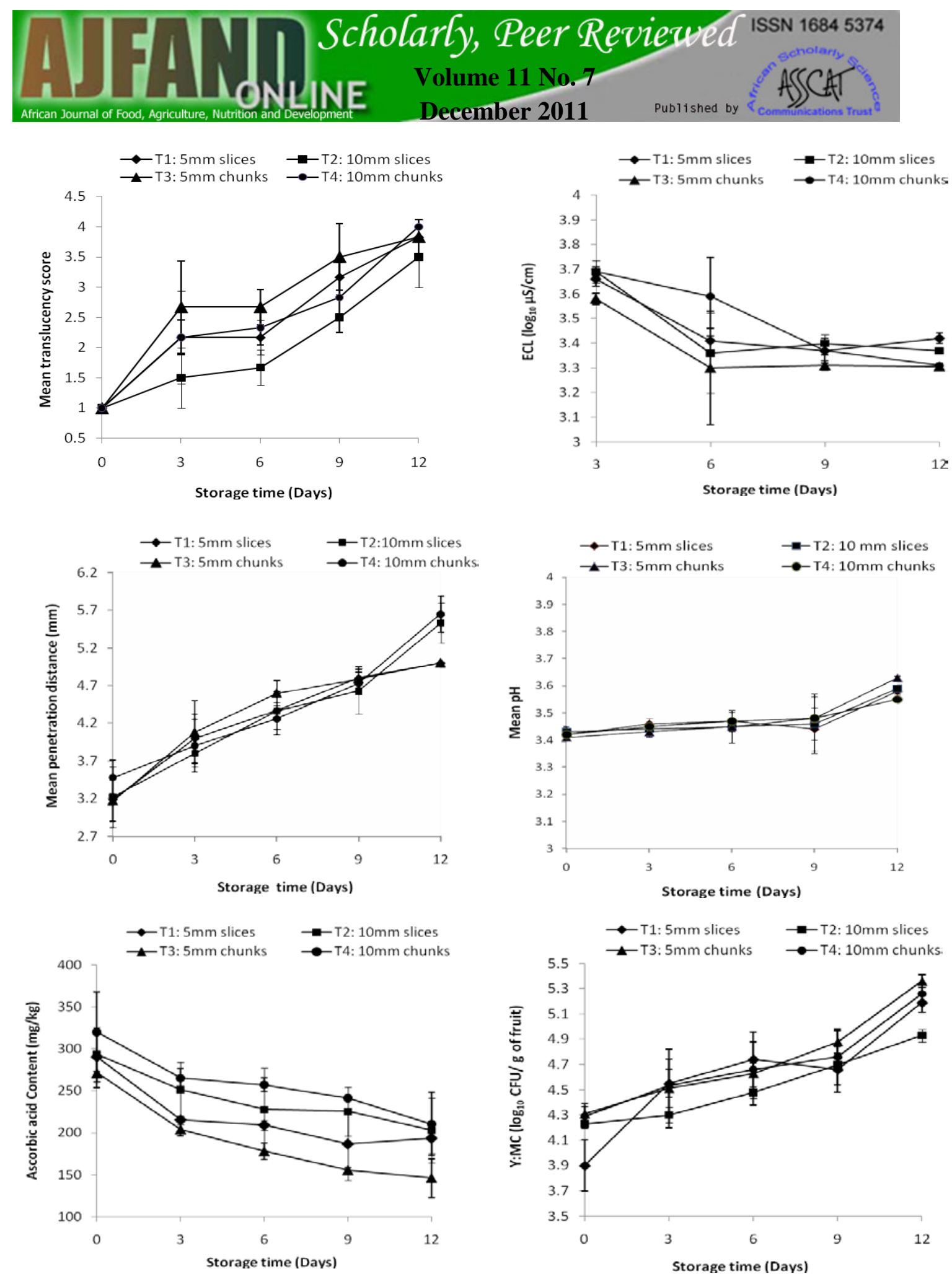

Figure 1: Effect of cutting-shapes and thicknesses on translucency score, electrical conductivity of leachate, penetration distance, $\mathrm{pH}$, ascorbic acid content and YMC of MPP, during 12 storage days at $4 \pm 1^{\circ} \mathrm{C}$. Vertical bars represent standard errors of mean. 
ECL

No leachate was produced by the treatments at day 0 and thus, the electrical conductivity could not be measured. There was a general significant drop $(\mathrm{p}<0.001)$ in the ECL over the 12 storage days for all treatments. Figure $1 \mathrm{~b}$ indicates that T1 had the highest ECL after 12 storage days, followed by T2, T3 and T4.

\section{Firmness}

There was a significant increase $(\mathrm{p}<0.001)$ in the mean penetration distance or a decrease in the firmness of the four treatments over the 12 storage days (Figure 1c) measured at a mean pineapple tissue temperature of $23 \pm 1^{\circ} \mathrm{C}$. Moreover, it was observed that T1 and T3 were penetrated fully at day 12 as compared to T2 and T4, whose maximum penetration of $10 \mathrm{~mm}$ was not reached after 12 storage days (Figure 1c).

$p H$

Mean $\mathrm{pH}$ increased significantly $(\mathrm{p}<0.001)$ over the storage period for all the treatmnents except T1, which exhibited a decrease in the mean $\mathrm{pH}$ between day 6 and 9 (Figure 1d).

\section{Ascorbic acid (AA) content}

The mean AA content of the four treatments decreased significantly $(p<0.001)$ with storage time except T1, which showed a slight increase in AA level between day 9 and 12 only (Figure 1e). Moreover, the reduction in AA level for all treatments was greatest during the first 3 storage days. Percent AA loss in $10 \mathrm{~mm}$ MPP slices was lowest (Table 2).

$Y M C$

YMC increased significantly $(\mathrm{p}<0.001)$ with time for all treatments except that $\mathrm{T} 1$ exhibited a decrease in YMC between day 6 and day 9 (Figure 1f). Moreover, it was observed that $\mathrm{T} 2$ had the lowest fungal load throughout the storage period time, except at day 0 , where $\mathrm{T} 1$ had the lowest YMC.

\section{DISCUSSION}

\section{Effect of cutting-shape}

Translucency score and penetration distance were greater in chunks than in slices (Table 1). Lana [24] explained that upon storage and maturation of tomato cuts, tomato tissues became more homogenous, causing less distortion in the light pathway through them and consequently, reducing light scattering and making the tomato cuts more translucent. The same explanation can be applied to MPP in this study. Since a slice had to be cut further to obtain a chunk, this could have resulted in additional bruises. Tissue damage may have raised ethylene production that elevated the activities of the leached texture-related enzymes in cell walls of fruit tissues [8, 11]. Moreover, a study on minimally processed papaya showed that softening enzymes like polygalacturonase are increased within 24 hours as compared to the whole fruit [25]. However, not all pineapple cultivars would respond similarly to this stress. Antoniolli et al. [6] reported that no ethylene synthesis was detected in the first 12

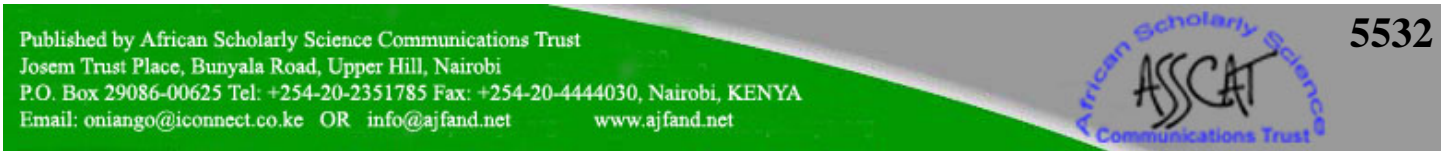


hours in MPP cv. 'Perola'. In contrast, Marrero and Kader [10] found an increase in ethylene production in MPP cv. 'Champaka' towards the end of its shelf-life. Since no data on ethylene production was reported for MPP cv. 'Queen Victoria' at $4^{\circ} \mathrm{C}$ and these enzymes were not evaluated in the present study, it could be suggested that as the enzymatic breakdown of these barriers progressed in the MPP, cell sap was gradually accumulated into the intercellular spaces causing homogeneity of the tissues and consequently, making translucency and penetration distance greater in chunks than in slices.

Pineapple chunks had a significantly higher YMC $(\mathrm{p}<0.01)$ than pineapple slices, when averaged over storage time (Table 1). Likewise, Arganosa et al. [13] reported that minimally processed papaya cubes stored at $4^{0} \mathrm{C}$ for 10 days had a higher YMC than papaya slices. One plausible explanation could be that the pineapple chunks exhibited a higher surface area to volume ratio (SA:V) (Table 2) and were presumably more wounded upon preparation than the slices. Therefore, rate of enzymatic hydrolyis of cell wall components was presumably enhanced in chunks, leading to more electrolyte leakage that favoured increased microbial growth. Hence, the microbes might have proliferated much faster on chunks than on slices.

\section{Effect of thickness}

Thickness had a significant effect on the flesh translucency $(p<0.01)$ and on penetration distance $(p<0.05)$ of the MPP. A thickness of $5 \mathrm{~mm}$ was shown to exhibit larger increase in translucency score and softening rate than that of $10 \mathrm{~mm}$, possibly because a thinner MPP has a greater SA:V than a thicker one (Table 2). Reduced firmness loss was also reported in MPP of several varieties, when treated with AA [26]. Low storage temperature and edible coatings have also been shown to be effective in delaying softening in many fresh-cut fruits [27].

\section{Interaction effect between cutting shape and thickness}

A significant interaction effect was noted between cutting-shapes and thicknesses on ECL $(p<0.05)$. ECL was greater in chunks than in slices, when the thickness doubled (Table 1). Doubling the thickness led to a decrease in the SA:V of both cut-styles (Table 2). However, $10 \mathrm{~mm}$ chunks exhibited a higher SA:V and they were probably more bruised during processing than the $10 \mathrm{~mm}$ slices. Hence, breakdown of cell walls was presumably higher in chunks, leading to more electrolyte leakage and higher ECL. Higher ECL and SA:V ratio may possibly lead to higher YMC values in chunks compared to slices. As the leachate dripped out from the MPP, some microbes growing on the pineapple tissues might have migrated to the leachate and continued their activities. These microbes not only extracted ions from the sap and leachate but they also infused hydrogen ions as a result of their metabolic activities [28]. Table 1 indeed shows that chunks had a higher YMC than slices. Hence, large amount of metabolic wastes were most probably excreted by these microorganisms in the leachate produced by MPP chunks that increased the ECL.

There was a strong significant interaction effect between cutting shapes and thicknesses on AA content of MPP $(\mathrm{p}<0.001)$. Since $5 \mathrm{~mm}$ chunks had a higher SA:V (Table 2), more of their surfaces were exposed to the $\mathrm{O}_{2}$ in the packs that allowed for

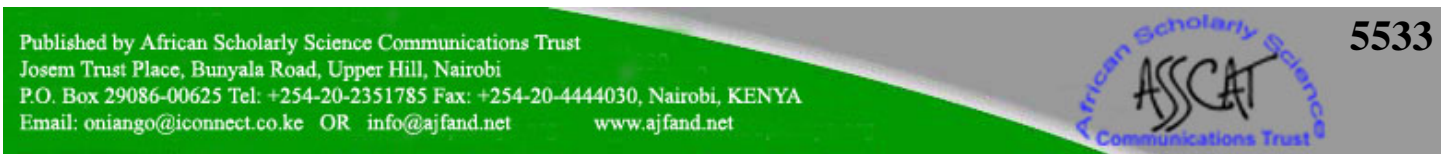


greater AA oxidation and loss as compared to the $10 \mathrm{~mm}$ slices. However, AA content of both cutting-shapes increased, when the thickness was doubled (Table 1). Increasing the thickness of MPP reduced its SA:V that slowed presumably the AA oxidation and thereby, minimizing AA loss.

\section{Effect of storage time}

Mean translucency scores increased in all treatments during the 12 storage days (Figure 1a). Mohammad and Wickham [26] reported similar trend for sealed packaged MPP slices of 'Sugar Loaf' cultivar. Apart from MPP, this disorder is of particular importance in other minimally processed produce like tomatoes [24] and papaya [12]. The bruised tissues during fruit peeling and cutting might have led to this condition [8]. Besides, hydrolysis of cell wall components during the translucency development contributes to texture loss of the produce. Hence, this can explain the significant decline $(\mathrm{p}<0.001)$ in the firmness of the four treatments with storage time (Figure 1c). Considerable firmness loss has been reported with storage of other minimally processed produce like papaya [1, 25], mango and pineapple [28].

Moreover, bruising of tissues might have leached other enzymes like ascorbate oxidase which in presence of $\mathrm{O}_{2}$ acted upon AA. The AA was then lost as Ldehydroascorbic acid (L-DHA) [3]. Hence, this could explain the significant decrease $(\mathrm{p}<0.001)$ in AA content in the MPP during storage time. However, the rate of AA loss was lower after day 3 (Figure 1e). This could be because of aerobic respiration and AA (being an antioxidant) mopping up $\mathrm{O}_{2}$, leading to its depletion in the pouches. Subsequently the AA oxidation process was slowed down after 3 storage days.

Microbial growth is influenced by the food $\mathrm{pH}$. The mean $\mathrm{pH}$ of all the treatments was initially 3.42 at $26.3^{0} \mathrm{C}$ and it significantly increased over storage time $(\mathrm{p}<0.001)$. This could be due to an acceleration of acids metabolism during respiration, leading to $\mathrm{pH}$ increase, as stated by Salveit [8]. The initial low $\mathrm{pH}$ of the MPP enabled fungi and other acid tolerant microorganisms to grow. Microbial spoilage of the MPP was however, not detected visually (no visible fungi and no surface slime) after 12 storage days. Besides, the YMC for all treatments was within the limit of $10^{2}-10^{6}$ prescribed by Di Cagno et al. [4].

\section{CONCLUSION}

MPP slices presented a more significant advantage than chunks in reducing translucency development, penetration distance (and hence, increased firmness) and YMC. As for the main effect of thickness, a thickness of $10 \mathrm{~mm}$ reduced significantly the translucency score and retained more the firmness and AA content than $5 \mathrm{~mm}$ thickness. In this investigation, the best treatment in maintaining most of the assessed quality attributes (translucency score, firmness, ascorbic acid content and YMC) for MPP during the storage period was $10 \mathrm{~mm}$ slices. 


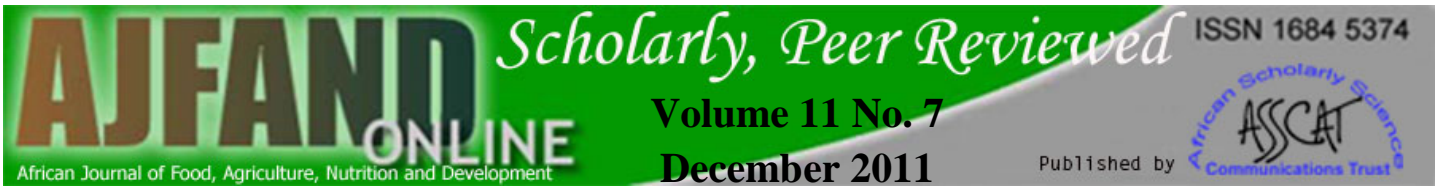

Table 1: Main and interaction effects due to cutting shape and thickness on translucency score, firmness and YMC, ECL and AA content, when averaged over storage time

\begin{tabular}{cccccc}
\hline & $\begin{array}{c}\text { Translucency } \\
\text { score }\end{array}$ & $\begin{array}{c}\text { Firmness } \\
\text { (penetration } \\
\text { distance/ mm) }\end{array}$ & $\begin{array}{c}\text { YMC(log } 10 \\
\text { CFU/g) }\end{array}$ & $\begin{array}{c}\text { ECL (log } 10 \\
\boldsymbol{\mu S} / \mathbf{c m})\end{array}$ & $\begin{array}{c}\text { AA content } \\
\text { (mg/kg) }\end{array}$ \\
\hline Cutting-shape & & & & & \\
Slices & $2.1 \pm 0.44$ & $4.29 \pm 0.02$ & $4.57 \pm 0.17$ & $3.46 \pm 0.07$ & $230 \pm 6.1$ \\
Chunks & $2.4 \pm 0.49$ & $4.37 \pm 0.02$ & $4.72 \pm 0.16$ & $3.43 \pm 0.08$ & $225 \pm 19.6$ \\
p - value & $* *$ & $* *$ & $* *$ & NS & NS \\
\hline Thickness & & & & \\
5mm & $2.4 \pm 0.40$ & $4.30 \pm 0.01$ & $4.67 \pm 0.17$ & $3.42 \pm 0.08$ & $205 \pm 8.1$ \\
10mm & $2.1 \pm 0.39$ & $4.36 \pm 0.02$ & $4.61 \pm 0.13$ & $3.48 \pm 0.08$ & $250 \pm 5.4$ \\
p - value & $* *$ & $*$ & NS & $*$ & $* * *$ \\
\hline
\end{tabular}

\section{Interaction}

$\begin{array}{cccc}\mathbf{p} \text { - value } & \text { NS } & \text { NS } & \text { NS }\end{array}$
significant at $5 \%$ level

Table 2: Calculated surface area to volume ratio (SA:V), \% mean penetration distance (MPD) and \% ascorbic acid loss after 12 storage days

\begin{tabular}{ccccc}
\hline Treatment & $\begin{array}{c}\text { Calculated } \\
\text { SA:V }\left(\mathbf{c m}^{-\mathbf{1}}\right)\end{array}$ & \%MPD & $\begin{array}{c}\text { \% Ascorbic acid loss on } \\
\text { fresh weight basis }\end{array}$ \\
\hline T1 & 5 mm slices & 4.47 & 85.4 & 33.4 \\
T2 & 10 mm slices & 2.47 & 43.1 & 30.9 \\
T3 & 5 mm chunks & 5.74 & 86.6 & 46.2 \\
T4 & 10 mm chunks & 3.73 & 44.1 & 34.3 \\
\hline
\end{tabular}




\section{REFERENCES}

1. Rivera-Lopez J, Vasquez-Ortiz FA, Ayala-Zavala JF, Sotelo-Mundo RR and GA Gonzalez Aguilar Cutting shape and Storage Temperature Affect Overall Quality of Fresh-cut Papaya cv. 'Maradol'. J. Food Sci. 2005; 70 (7): 3432-3439.

2. Gonzalez-Aguilar GA, Ruiz-Cruz S, Soto-Valdez H, Vasquez-Ortis F, Pacheco-Aguilar $\mathbf{R}$ and $\mathbf{C}$ Yi Wang Biochemical Changes of Fresh-cut Pineapple Slices Treated with Antibrowning Agents. Int. J. Food Sci. Tech. 2005; 40: 377-381.

3. Beaulieu JC and RJ Gorny Fresh-cut Fruits. [Online]. Available at: http://www.ba.ars.usda.gov/hb66/146freshcutfruits.pdf. United States Department of Agriculture, USA. [Date accessed: $5^{\text {th }}$ September 2009].

4. Di Cagno R, Cardinali G, Minervini G, Antonielli L, Rizzello CG, Ricciuti $\mathbf{P}$ and $\mathbf{M}$ Gobbetti Taxonomic Structure of the Yeasts and Lactic Acid Bacteria Microbiota of Pineapple (Ananas comosus L. Merr.) and Use of Autochthonous Starters for Minimally Processing. Food Microbiol. 2009.

5. Singh RP Scientific Principles of Shelf-life Evaluation. In: Man, CMD. and Jones, AA. (Eds). Shelf-life Evaluation of Foods. Blackie Academic and professional, Chapman and Hall. 1994; 3.

6. Antoniolli LR, Benedetti BC, Sigrist JMM and NFA Silveira Quality Evaluation of Fresh-cut 'Perola' Pineapple Stored in Controlled Atmosphere. Bra. Con. Food Sci. Tech. 2007; 27: 530-534.

7. Pittia P, Nicoli MC, Comi G and R Massini Shelf-life Extension of Freshlike Ready-to-use Pear Cubes. J. Sci. Food Agric. 1999; 79: 957-960.

8. Saltveit RE Physical changes in processed fruits and vegetables. In: TomásBarberán, FA and Robins, RJ (Eds). Phytochemistry of Fruits and Vegetables. Oxford University Press, New York, USA. 2001; 206-217.

9. Cantwell MI and TV Suslow Postharvest Handling Systems: Fresh-cut Fruits and Vegetables. In: Kader AA (Ed). Postharvest Technology of Horticultural Crops. University of California, USA. 2002; 445, 447, 448, 451-460.

10. Marrero A and AA Kader Optimal Temperature and Modified Atmosphere for Keeping Quality of Fresh-cut Pineapples. Postharv. Biol. Tech. 2005; 39: 163-168.

11. Shewfelt RL and SE Prussia Postharvest Handling - A Systems Approach, (1993). pp 100-115, 126-133, 140-144, 212-217, 263-267. Academic Press Inc., San Diego, California, United States of America. 
12. O'Connor-Shaw RE, Roberts R, Ford AL and SM Nottingham Shelf-life of Minimally Processed Honeydew, Kiwifruit, Papaya, Pineapple and Cantaloupe. J. Food Sci. 1994; 59: 1202-1203.

13. Arganosa SJ, Raposo MFJ, Teixeira PCM and MMB Morais Effect of Cut-type on Quality of Minimally Processed Papaya. J. Sci. Food Agric. 2008; 88: 2050-2060.

14. Teixeira GHDA, Durigan JF, Mattiuz BH and OD Rossi Junior Fresh-cut of 'Formosa' Papaya. Bra. Con. Food Sci. Tech. 2001; 21 (1): 47-50. [Online]. Available at: http://www.scielo.br/pdf/cta/v21n1/5363.pdf. [Date accessed: $30^{\text {th }}$ March 2010].

15. Antoniolli LR, Benedetti BC, Sigrist JMM, Souza Filho MM and RE Alves Metabolic activity of fresh-cut 'Pérola' pineapple as affected by cut shape and temperature. Bra. J. Plant Physiol. 2006; 18 (3): 413-417.

16. Agricultural Research and Extension Unit. Pineapple Processing, Agribusiness Prospects. Republic of Mauritius. 2006.

17. Haff RP, Slaughter DC, Sarig $\mathbf{Y}$ and A Kader X-ray assessment of translucency in pineapple. J. Food Process. Preserv. 2006; 30: 527-530.

18. Kader AA Pineapple - Recommendation for Maintaining Postharvest Quality. In: Kader, AA. (Ed). Postharvest Technology. University of California, Davis. 2008; 49-50.

19. Marangoni AG, Palma T and DW Stanley Membrane Effects in Postharvest Physiology. Postharv. Biol. Tech. 1996; 7 (3): 193-194.

20. Clesceri LS, Eaton AD and AE Greenberg Electrical conductivity 2004. [online]. Available at:

http://ecorestoration.montana.edu/mineland/guide/analytical/chemical/water/e c.htm\#. [Date accessed: $10^{\text {th }}$ November 2009].

21. International Organization for Standardization. Fruit and Vegetable products - Determination of pH. International Standard, ISO 1842:1991. Switzerland, ISO. 1991.

22. Association of Official Analytical Chemists (AOAC) Official Methods of Analysis of the Association of Official Analytical Chemists, Volume II, Association of Analytical Chemists, USA. 1995, 16-18.

23. International Organization for Standardization (ISO) Microbiology General guidance for enumeration of yeasts and moulds - Colony count technique at $25^{\circ} \mathrm{C}$. International Standard, ISO 7954:2003. Switzerland, ISO. 2003. 
24. Lana MM Modelling Quality of Fresh-cut Tomato Based on Stage of Maturity and Storage Conditions. [online]. Available at:

http://library.wur.nl/wda /dissertations/dis3802.pdf. Wageningen, Netherlands, 2005. [Date accessed: $5^{\text {th }}$ October 2009].

25. Karakurt Y and DJ Huber Activities of Several Membrane and Cell Wall Hydrolases, Ethylene Biosynthetic Enzymes, and Cell Wall Polyuronide Degradation During Low Temperature Storage of Intact and Fresh-cut Papaya Fruit. Postharv. Biol. Tech. 2003; 28: 219-229.

26. Mohammed $\mathbf{M}$ and LD Wickham Effect of Antioxidants on Postharvest Quality Attributes of Fresh-cut Pineapples. Acta Hort. 2005; 666: 309- 311.

27. Martín-Belloso $\mathbf{O}$ and R Soliva-Fortuny Effect of Modified Atmosphere Packaging on the Quality of Fresh-cut Fruits. Stew. Postharv. Rev. 2006; 1 (3): 1-4.

28. Martinez-Ferrer M, Harper C, Perez-Munoz F and F Chaparro Modified Atmosphere Packaging of Minimally Processed Mango and Pineapple Fruits. J. Food Sci. 2002; 67 (9): 3365-3371. 